\title{
COMPORTAMENTO DAS CULTIVARES CABERNET SAUVIGNON E SYRAH EM DIFERENTES PORTA-ENXERTOS
}

\author{
Yield-related performance of cv Cabernet Sauvingnon and Petite Syrah \\ on different rootstocks
}

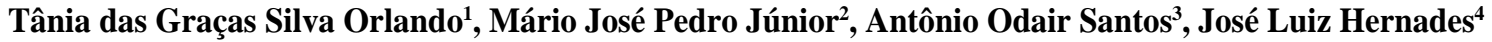

\begin{abstract}
RESUMO
As cultivares Cabernet Sauvignon e Syrah são destinadas à elaboração de vinhos tintos jovens ou de guarda bastante difundidas em diversas zonas vitivinícolas de todo o mundo. No Brasil, são utilizadas principalmente no Rio Grande do Sul e Vale do Rio São Francisco. Atualmente, produtores da região de Jundiaí, SP, têm demonstrado interesse na utilização de tais cultivares com intuito de obter vinhos de qualidade superior aos originários de cultivares americanas. Por isso, realizou-se o estudo do comportamento

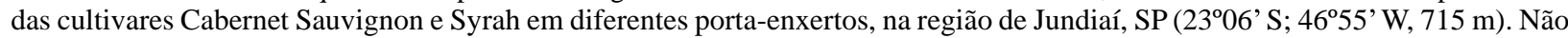
houve influência dos diferentes porta-enxertos sobre o comportamento da cultivar Cabernet Sauvignon. O porta-enxerto IAC 571-6 'Jundiaí' tendeu a conferir colheita tardia na cultivar Syrah. Os porta-enxertos IAC 572 'Jales' e IAC 571-6 'Jundiaí' conferiram maior produção a cultivar Syrah. A cultivar Syrah apresentou-se como boa opção de plantio para obtenção de vinho de qualidade na região.
\end{abstract}

Termos para indexação: Uva, vinho, qualidade.

\begin{abstract}
Grapevines cv. Cabernet Sauvignon and Syrah are largely used for high quality vine making all around the world. In Brazil they are concentrated moreover, at the Rio Grande do Sul state and in the São Francisco Valley. Producers from Jundiaí region (São Paulo state) have been interested in such cultivars for improved quality vine making as they generally use american cultivars for that propose. Aiming study the performance of cv Cabernet Sauvingnon and Syrah, cultivated over different rootstocks an experiment was conducted in the region of Jundiaí (SP) (2306' S; 46 $55^{\prime}$ W, $715 \mathrm{~m}$ ). Results showed that there wasn't influence of different rootstocks on the performance of both analyzed cultivars. It was observed a trend of the rootstock IAC 571-6 'Jundiaí' to improve final yield of cv Syrah. The Rootstocks IAC 572 'Jales' and IAC 571-6 'Jundiaí' combined to Syrah resulted in the highest yield in the experiment. The Syrah shows itself to be a good alternative when planting for quality vine making in the region of the experiment.
\end{abstract}

Index terms: Grapevine, rootstocks, Cabernet Sauvignon, Syrah.

(Recebido em 12 de dezembro de 2006 e aprovado em 5 de maio de 2007)

\section{INTRODUÇÃO}

A cultivar Cabernet Sauvignon originou-se na região de Bordeaux, França, e difundiu-se pela maioria das regiões vitícolas de todo mundo. Foi introduzida no Brasil em 1921, mas somente após 1980 que seu plantio começou a se tornar expressivo na Serra Gaúcha.

É de brotação e maturação tardia e relativamente vigorosa. Com ramos novos de porte ereto, de média produção e elevada qualidade de vinificação (FREGONI, 1998; GALET, 1976; HIDALGO, 1993; WINKLER et al., 1974). A uva tem gosto particular e elevada tolerância à podridão do cacho (RIZZON \& MIELE, 2002). Seu vinho, de intensa cor rubi, encorpado e de agradável buquê, é considerado u m dos melhores do mundo (CATALUNHA, 1991).

A cultivar Syrah ou ainda Shiraz é uva tinta que envelhece até por meio século. Muito bem adaptada aos climas quentes, como o sul da França e com excelente adaptação em terras australianas, para onde foi levada em 1832.

Foi disseminada por outras partes do mundo após 1970. Crescendo bem em inúmeras áreas, produz vinhos complexos e distintos, escuros, alcoólicos e com aromas e sabores de especiarias (ALBERT, 2004).

No Brasil, duas áreas são distintas no plantio das cultivares Cabernet Sauvignon e Syrah. O Rio Grande do Sul investe no plantio da Cabernet Sauvignon, enquanto

\footnotetext{
1Engenheira Agrônoma, Doutora - Centro Avançado de Pesquisa Tecnológica do Agronegócio de Frutas/CAPTA-Frutas - Instituto Agronômico/IAC Avenida Luiz Pereira dos Santos, 1500 - Corrupira - 13214-820 - Jundiaí, SP - tania@ufla.br

${ }^{2}$ Engenheiro Agrônomo, Doutor - Centro de Ecofisiologia e Biofísica - Instituto Agronômico/lAC - Avenida Theodureto de Almeida Camargo, 1500 - Cx. P. 28 - 13001-970 - Campinas, SP - mpedro@iac.sp.gov.br

${ }^{3}$ Engenheiro Agrônomo, Doutor - Centro de Engenharia e Automação/CEA - Instituto Agronômico/IAC - Rodovia Dom Gabriel Paulino Bueno Couto, Km 65 - Aeroporto - Cx. P. 26 - 13201-970 - Jundiaí, SP - odairsan@iac.sp.gov.br

${ }^{4}$ Biólogo, Mestre - Centro Avançado de Pesquisa Tecnológica do Agronegócio de Frutas/CAPTA-Frutas - Instituto Agronômico/IAC - Avenida Luiz Pereira dos Santos, 1500 - Corrupira - 13214-820 - Jundiaí, SP - jlhernandes@iac.sp.gov.br
} 
no Vale do Submédio São Francisco a Syrah é a principal uva tinta para vinho cultivada na região.

O Estado do Rio Grande do Sul produziu 232.355.918 litros de vinho e derivados em 2003 e no Vale do São Francisco em torno de 5.000.000 de litros por ano (PERNAMBUCO, 2004; UVIBRA, 2003) enquanto os últimos dados registrados para São Paulo, em 1999, foi de 1.122.257 litros (EMBRAPA, 2003).

São Paulo destaca-se como segunda área vitícola e maior Estado produtor de uvas de mesa do País. Atualmente o Estado possui cerca de 39.000 .000 de plantas, sendo 36.083.000 de uvas comuns e 3.080.000 de uvas finas (SOUSA \& MARTINS, 2002). Desse montante, $97 \%$ da área plantada situa-se na região de Campinas e Jundiaí (FERREIRA, 2003).

Embora com utilização menos expressiva de uva para vinho, viticultores da região de Jundiaí vêm demonstrando interesse na implementação de áreas com uvas que propiciem a obtenção de vinhos de qualidade superior àqueles elaborados na região, oriundas de cultivares americanas. Assim, a demanda por pesquisas na área torna-se essencial ao desenvolvimento da vitivinicultura regional.

Dentre os trabalhos em desenvolvimento, o comportamento de cultivares vinííferas sob as condições climáticas regionais e a busca da combinação ideal entre porta-enxerto tem sido preconizados, uma vez que diversas variáveis atuam sobre essas combinações.

Neste contexto, objetivou-se com este trabalho avaliar o comportamento de das cultivares Cabernet Sauvignon e Syrah em diferentes porta-enxertos.

\section{MATERIAL E MÉTODOS}

O trabalho foi realizado no CAPTA-Frutas-IAC, localizado em Jundiaí, SP, situado a $715 \mathrm{~m}$ de altitude $23^{\circ} 06^{\prime} \mathrm{S}$ de latitude e $46^{\circ} 55^{\prime}$ de longitude, cujo clima apresenta temperatura média anual de $20,9^{\circ} \mathrm{C}$, com média do mês mais frio inferior a $18^{\circ} \mathrm{C}$ e mais quente superior a $22^{\circ} \mathrm{C}$, precipitação média anual de $1383 \mathrm{~mm}$.

Os porta-enxertos foram implantados em janeiro de 2000, seguindo o espaçamento de 2,0 X 1,0 m e enxertados em julho do mesmo ano. $\mathrm{O}$ vinhedo foi conduzido em treliça em V, promovendo maior aeração e incidência de raios solares sobre o dossel vegetativo. A poda, efetuada nesse mesmo período, foi mista, deixando-se 2 gemas por esporão na poda curta e 10 a 12 gemas na poda longa.

O delineamento experimental utilizado foi em blocos casualizados com 8 tratamentos, representado por 4 portaenxertos: ‘Riparia do Traviú', IAC 766 'Campinas', IAC 572 'Jales' e IAC 571-6 'Jundiaí' e 2 cultivares: Cabernet
Sauvignon e Syrah. Foram utilizadas 4 repetições e avaliadas 4 plantas por parcela, perfazendo 128 plantas.

O acompanhamento do crescimento dos ramos foi efetuado semanalmente, com auxílio de trena, medindo-se em dois ramos situados na porção mediana da planta. As medidas iniciaram-se quando os ramos apresentavam cerca de $5 \mathrm{~cm}$ e findaram na estabilização de seu crescimento.

$\mathrm{O}$ acompanhamento fenológico foi realizado de agosto de 2003 a janeiro de 2004 seguindo as fases de brotação, floração e maturação de acordo com a metodologia descrita por Carbonneau (1981).

A contagem dos cachos foi efetuada previamente à colheita com intuito de controlar possíveis perdas por ataque de insetos, pássaros ou outras eventualidades.

Por ocasião da colheita foram avaliadas produção, rendimento em polpa, casca e semente, sólidos solúveis, acidez titulável e $\mathrm{pH}$. A produção foi obtida pela pesagem dos frutos colhidos em cada tratamento. Por conseguinte, retiraram-se 100 bagas de cada tratamento e pesadas. Cascas, polpas e sementes foram separadas. As cascas foram pesadas, a polpa utilizada em análises físico-químicas e as sementes lavadas, secas em papel toalha, pesadas e contadas.

Os teores de sólidos solúveis foram obtidos por refratometria, a acidez titulável por titulometria com $\mathrm{NaOH}$ $0,1 \mathrm{~N} \mathrm{e} \mathrm{o} \mathrm{pH}$ por leitura direta da amostra.

\section{RESULTADOS E DISCUSSÃO}

Pela observação dos resultados dispostos na Tabela 1, constatou-se que não houve influência do porta-enxerto sobre o crescimento dos ramos, embora os porta-enxerto IAC 572 'Jales' e IAC 571-6 'Jundiaí' tenham apresentado tendência em conferir maior desenvolvimento.

Os porta-enxertos IAC 572 'Jales' e IAC 571-6 'Jundiaî' conferiram maior produção à cultivar Syrah. Embora não tenham ocorrido diferenças significativas para a cultivar Cabernet Sauvignon, os dados apresentados demonstram tendência do porta-enxerto IAC571-6 'Jundiaí' propiciar maior produção, em relação aos demais portaenxertos estudados.

Nesse aspecto, Santos et al. (2004) estudando o comportamento da cv. Cabernet Sauvignon em Jundiaí, verificaram que os porta-enxertos IAC 766 'Campinas' e o IAC 572 'Jales' proporcionaram maior produção, tanto em ambiente modificado quanto a céu aberto, em comparação com o Riparia do Traviú. Na região de Mocóca, SP, Terra et al. (2001) relataram que nas safras 1986 e 1987 os porta-enxertos IAC 572 'Jales' e 571-6 'Jundiaí'_conferiram maior produção às cultivares Isabel e Concord. Em Caldas, MG, Alvarenga et al. (2002) 
Tabela 1 - Médias do comprimento final dos ramos, número de cachos por planta e produção das cultivares Cabernet Sauvignon e Syrah em diferentes porta-enxerto, safra 2004.

\begin{tabular}{|c|c|c|c|c|c|c|}
\hline \multirow[b]{2}{*}{ P.E.ICv. } & \multicolumn{2}{|c|}{ Comprimento Ramos $(\mathrm{cm})$} & \multicolumn{2}{|c|}{$\mathrm{N}^{\circ} \cdot$ cachos $/ \mathrm{pl}^{-1}$} & \multicolumn{2}{|c|}{ Produção $\left(\mathrm{Kg} / \mathrm{pl}^{-1}\right)^{*}$} \\
\hline & CS & $S$ & CS & $S$ & $\mathrm{CS}$ & $S$ \\
\hline Ripária do Traviú & 51,10 & 94,55 & 8,23 & $9,79 \quad b$ & 1,10 & $1,14 \quad b$ \\
\hline IAC 766 'Campinas' & 57,47 & 97,73 & 10,69 & $10,31 \quad b$ & 1,17 & $1,29 \mathrm{~b}$ \\
\hline IAC 572 'Jales' & 59,10 & 102,75 & 13,50 & $15,12 \mathrm{a}$ & 0,94 & 2,51 a \\
\hline IAC 571-6 'Jundiaí' & 65,85 & 116,47 & 14,64 & $15,37 \mathrm{a}$ & 2,06 & 2,42 a \\
\hline $\mathrm{F}$ & $1,03 \mathrm{~ns}$ & $0,69 \mathrm{~ns}$ & $1,15 \mathrm{~ns}$ & $17,94 * *$ & $1,01 \mathrm{~ns}$ & $5,77 * *$ \\
\hline DMS (Scott-Knott 5\%) & 0,42 & 0,58 & 0,38 & 0,00 & 0,45 & 0,03 \\
\hline $\mathrm{CV}(\%)$ & 20,47 & 22,61 & 45,74 & 11,23 & 65,64 & 28,38 \\
\hline
\end{tabular}

*Médias seguidas de mesma letra, não diferem entre si pelo teste Scott-Knott a 5\% de probabilidade.

CS: Cabernet Sauvignon; S: Syrah

verificaram a superioridade de produção para a cultivar Niágara Rosada sobre o porta-enxerto IAC 572 'Jales' que foi semelhante ao IAC 766 'Campinas' e ‘Ripária do Traviú,, quando comparados ao Gravesac, 420-A, 196-17 Cl, RR 101-14 e pé-franco. Esses mesmos autores observaram que o IAC 572 'Jales' conferiu maior tamanho de cacho, confirmando os dados observados para a cultivar Syrah, no presente trabalho.

Outro fator positivo para os porta-enxertos IAC 572 'Jales' e IAC 571-6 'Jundiaí' é a tolerância desses materiais à pérola-da-terra (Eurhizococcus brasiliensis (Hempel)), importante praga que ataca as raízes da videira, presente nos solos de Jundiaí/SP, principalmente quando comparados com 'Riparia do Traviú', porta-enxerto tradicionalmente utilizado nessa região (BOTTON et al., 2000; LEÃO \& SOARES, 2000; LOURENÇÃO et al., 2002; POMMER, 2000).

As curvas explícitas na Figura 1 demonstram que o crescimento dos ramos das cultivares Cabernet Sauvignon e Syrah apresentaram crescimento linear. A cultivar Syrah apresentou desenvolvimento bastante acentuado e contínuo após o inicio da floração (26/09/03). Contudo, as cultivares cessaram o crescimento antes do início da maturação. Para a videira é comum o crescimento dos ramos primários cessarem ao redor do vèrassion $(\mathrm{JACKSON}$, 1999). A interrupção mais adiantada no crescimento dos ramos, provavelmente está relacionada a disponibilidade térmica e hídrica do local do experimento. Os dados demonstraram também, que o porta-enxerto 'IAC 571-6' apresentou tendência em conferir maior vigor às plantas, em ambas cultivares.

As avaliações fenológicas mostraram que ambas cultivares apresentaram ciclo de 13 a 17 dias entre a poda e o início da brotação, 41 a 42 dias entre o início de brotação e floração, 65 a 66 dias entre início de floração e maturação, 43 a 47 dias entre início da maturação e colheita, completando o ciclo aos 165 dias após a poda (Tabela 2).

Neste contexto (AMORIM \& CAMARGO, 2003), estudando o comportamento fenológico da cv. Syrah enxertada em IAC 572 'Jales', observaram que sob as condições climáticas do Vale Submédio São Francisco, as plantas apresentaram ciclo médio de 135 dias, reduzindo em 44 dias quando comparado com as condições de Bento Gonçalves, RS. Assim, nas condições climáticas de Jundiaí, o ciclo foi reduzido em 14 dias quando comparado a Bento Gonçalves e atrasado em 30 dias em relação ao Vale do Submédio São Francisco.

Foram observadas diferenças significativas apenas no final da maturação para os frutos da cv. Syrah, na qual os porta-enxertos ‘Riparia do Traviú_, IAC 766 'Campinas' e IAC 572 'Jales' conferiram a antecipação enquanto o IAC 571-6 'Jundiaí' provocou atraso de 06 dias na maturação dos frutos.

Embora, a colheita tenha sido efetuada no mesmo período para todos os tratamentos, por problemas de ataque de insetos, acredita-se que as plantas enxertadas em IAC 571-6 'Jundiaí' teriam sido colhidas após os demais tratamentos, como tenderam os resultados.

Não foram observadas diferenças para as características rendimento em polpa, casca e sementes, teor de sólidos solúveis, acidez titulável e pH do frutos em ambas cultivares analisadas (Tabela 3). Resultados semelhantes de sólidos solúveis foram encontrados para a cv. Cabernet Sauvignon sobre os mesmos porta-enxertos, em ambiente parcialmente modificado e a céu aberto, na 
Cabernet Sauvignon

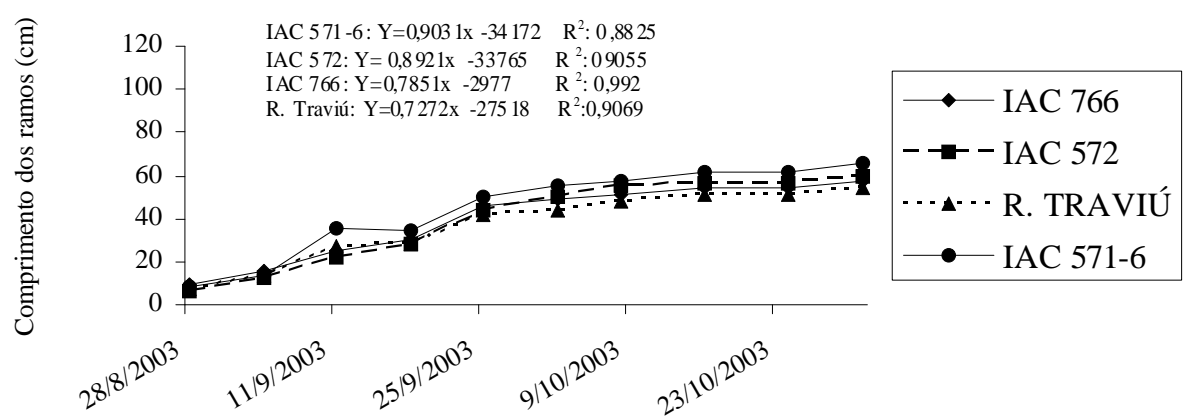

Data

Syrah

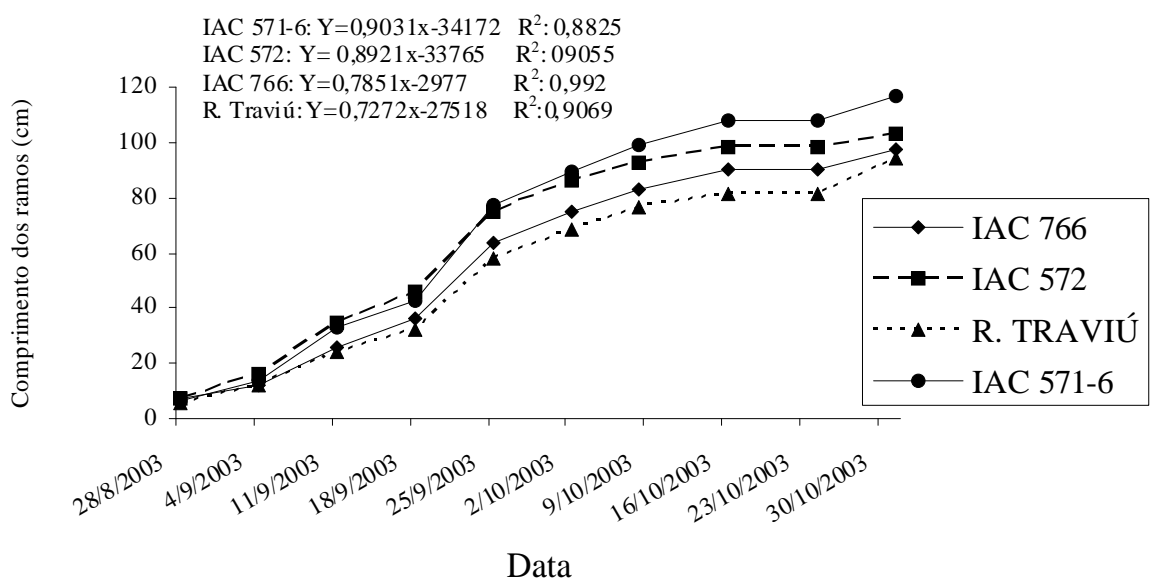

Figura 1 - Curvas de crescimento dos ramos das cultivares Cabernet Sauvignon e Syrah em diferentes porta-enxertos, safra 2004

região de Jundiaí por Ferreira (2003). Muito embora os valores de rendimento em casca não tenham se diferenciado estatiisticamente, para a cultivar Cabernet Sauvignon, é notório que os maiores valores encontrados para esta cultivar indicam uma tendência de melhor relação casca/polpa, portanto evidenciando um maior potencial para extração de polifenóis durante a maceração.

Quando consideramos isoladamente os valores obtidos, verificamos que para a cultivar Cabernet Sauvignon, o teor de sólidos solúveis encontrou-se em $16,95^{\circ}$ Brix, bastante próximo a valores determinados para a mesma cultivar no Rio Grande do Sul que permaneceu em torno de $18^{\circ}$ Brix (RIZZON \& MIELE, 2002).

A acidez titulável teve valor médio de 144,56 meq/L, pouco superior os $120 \mathrm{meq} / \mathrm{L}$ (média de seis anos), encontrados por Rizzon \& Miele (2002). Contudo, segundo Rizzon et al. (1998) em ambos os casos os valores não são considerados elevados, pois durante o processo de vinificação ocorre considerável redução da acidez titulável, principalmente pela salificação e precipitação do ácido tartárico e à fermentação malolática. De fato, muito embora a composição da acidez da uva seja o principal fator de controle da acidez do mosto e do vinho, esta propriedade pode ser significantemente alterada ela atividade microbiana, durante a fermentação (FLEET, 1992). Além disso, existeem vários estilos potenciais de vinhos, para os quais existirão diferentes níveis para a ótima acidez, desde que considerados os limites técnicos já estabelecidos pela experiência enológica.

$\mathrm{O} \mathrm{pH}$ do mosto permaneceu abaixo de 3,38, outro indicativo positivo para elaboração de vinho Valores 
Tabela 2 - Duração média dos estádios fenológicos, em dias após a poda (DAP), com respectivas datas de ocorrência para videira, cultivares Cabernet Sauvignon e Syrah sob diferentes porta-enxertos, safra 2004.

\begin{tabular}{|c|c|c|c|c|c|c|c|}
\hline \multirow[b]{3}{*}{ P.e.ICv. } & \multicolumn{7}{|c|}{ Dias após a poda (DAP) } \\
\hline & IB & FB & IF & $\mathrm{FF}$ & $\mathrm{IM}$ & FM & Colheita \\
\hline & \multicolumn{7}{|c|}{ Cabernet Sauvignon } \\
\hline Ripária do Traviú & 14 & 17 & 56 & 61 & 120 & 133 & 165 \\
\hline IAC 766 'Campinas' & 13 & 18 & 65 & 60 & 117 & 131 & 165 \\
\hline IAC 572 'Jales' & 17 & 18 & 56 & 61 & 118 & 132 & 165 \\
\hline IAC 571-6 Jundiaí' & 15 & 22 & 55 & 60 & 119 & 135 & 165 \\
\hline $\mathrm{F}$ & $0,57 \mathrm{~ns}$ & $0,75 \mathrm{~ns}$ & $1,94 \mathrm{~ns}$ & $1,54 \mathrm{~ns}$ & $2,83 \mathrm{~ns}$ & $3,42 \mathrm{~ns}$ & \\
\hline DMS (Scott-Knott 5\%) & 0,64 & 0,55 & 0,19 & 0,27 & 0,1 & 0,07 & \\
\hline $\mathrm{CV}(\%)$ & 23,95 & 24,33 & 0,62 & 1,76 & 1,43 & 1,35 & \\
\hline Data & $15 / 08 / 03$ & $19 / 08 / 03$ & 02/10/03 & 28/09/03 & 27/11/03 & $12 / 12 / 03$ & $13 / 01 / 04$ \\
\hline P. E.ICv. & & & & Syrah & & & \\
\hline Riparia do Traviú & 15 & 19 & 57 & 63 & 118 & $133 \mathrm{~b}$ & 165 \\
\hline IAC 766 Campinas' & 15 & 19 & 57 & 62 & 118 & $132 \mathrm{~b}$ & 165 \\
\hline IAC 572 'Jales' & 15 & 19 & 57 & 62 & 120 & $135 \mathrm{~b}$ & 165 \\
\hline IAC 571-6 Jundiaí' & 16 & 19 & 57 & 62 & 122 & $139 \mathrm{a}$ & 165 \\
\hline $\mathrm{F}$ & $0,06 \mathrm{~ns}$ & $0,16 \mathrm{~ns}$ & $0,19 \mathrm{~ns}$ & $1,44 \mathrm{~ns}$ & $2,62 \mathrm{~ns}$ & $15,91 * *$ & \\
\hline DMS (Scott-Knott 5\%) & 0,98 & 0,92 & 0,90 & 0,29 & 0,11 & 0,00 & \\
\hline $\mathrm{CV}(\%)$ & 6,96 & 6,20 & 1,93 & 1,14 & 1,81 & 1,10 & \\
\hline Data & $15 / 08 / 03$ & $19 / 08 / 03$ & 26/09/03 & 01/10/03 & $30 / 11 / 03$ & $\begin{array}{l}12 / 12 / 03 \\
18 / 12 / 03\end{array}$ & $13 / 01 / 04$ \\
\hline
\end{tabular}

*Médias seguidas de mesma letra, não diferem entre si pelo teste Scott-Knott a 5\% de probabilidade.

IB: Início da brotação; IF: Início da floração; IM: Início da Maturação; FB: Fim da brotação; FF: Fim da floração; FM: Fim da Maturação

mais elevados pressupõem absorção elevada de K pela videira e conseqüente salificação dos ácidos orgânicos, especialmente os tartáricos (BLOUIN \& GUIMBERTEAU, 2000; CÀSTINO, 1992; WINKLER et al., 1974).

Para a cultivar Syrah, os dados obtidos sugerem maior capacidade desta cultivar em acumular sólidos solúveis, nas condições de microclima do dossel, no experimento. Muito embora o teor de sólidos solúveis, isoladamente não seja um indicador robusto da qualidade potencial_para vinificação, o mesmo sugere que a cultivar apresentou melhor resposta e adaptação às condições reinantes, quanto ao manejo e incidência de variáveis do microclima , acumulando $17,18^{\circ}$ Brix de sólidos solúveis. Os valores para Brix são um pouco superiores aos valores obtidos por Lima et al. (2003) na região do Vale do Submédio São Francisco que situaram-se em $16,5^{\circ}$ Brix. Se, por um lado, os dados do experimento não são suficientes para concluir sobre o potencial de sabor e aroma- para -possível vinificação da uva desta cultivar, por outro lado, dentre os valores medidos, a acidez titulável, que permaneceu em $113,49 \mathrm{meq} / \mathrm{L}$ e o $\mathrm{pH}$ que evidenciou valorees de 3,52, demonstram que a uva obtida apresenta parâmetros qualitativos que estão dentro da faixa aceitável para a vinificação (ZOECKLEIN et al., 1999). 
ORLANDO, T. das G. S. et al.

Tabela 3 - Médias do rendimento de polpa, casca e sementes, teor de sólidos solúveis, acidez titulável e pH dos frutos das cultivares Cabernet Sauvignon e Syrah em diferentes porta-enxerto, safra 2004.

\begin{tabular}{lcccccc}
\hline & \multicolumn{2}{c}{ Rendimento em polpa (\%) } & \multicolumn{2}{c}{ Rendimento em casca (\%) } & \multicolumn{3}{c}{ Rendimento sementes (\%) } \\
\cline { 2 - 7 } P.e.ICv & $\mathrm{CS}$ & $\mathrm{S}$ & $\mathrm{CS}$ & $\mathrm{S}$ & $\mathrm{CS}$ & $\mathrm{S}$ \\
\hline Ripária do Traviú & 51,70 & 61,32 & 42,87 & 33,75 & 5,42 & 4,93 \\
IAC 766 & 51,61 & 56,21 & 43,14 & 38,90 & 5,24 & 4,87 \\
IAC 572 & 51,06 & 60,60 & 43,85 & 34,63 & 5,04 & 4,76 \\
IAC 571-6 & 50,47 & 60,44 & 43,89 & 34,54 & 5,67 & 5,51 \\
\hline F & $0,17 \mathrm{~ns}$ & $1,96 \mathrm{~ns}$ & $0,22 \mathrm{~ns}$ & $2,23 \mathrm{~ns}$ & $0,42 \mathrm{~ns}$ & $0,57 \mathrm{~ns}$ \\
DMS (Scott-Knott 5\%) & 0,91 & 0,19 & 0,88 & 0,15 & 0,75 & 0,65 \\
CV (\%) & 5,39 & 5,5 & 5,08 & 8,81 & 15,45 & 17,74 \\
\hline & Sólidos solúveis ( ${ }^{\circ}$ Brix) & Acidez Titulável (meq/L) & & $\mathrm{pH}$ \\
Porta-enxertolCultivar & $\mathrm{CS}$ & $\mathrm{S}$ & $\mathrm{CS}$ & $\mathrm{S}$ & $\mathrm{CS}$ & $\mathrm{S}$ \\
\hline Ripária do Traviúy & 16,90 & 17,15 & 141,61 & 117,60 & 3,32 & 3,46 \\
IAC 766 & 17,35 & 17,65 & 143,57 & 113,89 & 3,29 & 3,59 \\
IAC 572 & 16,12 & 17,07 & 150,92 & 113,19 & 3,38 & 3,53 \\
IAC 571-6 & 17,42 & 16,85 & 142,15 & 109,27 & 3,33 & 3,49 \\
\hline F & $3,14 \mathrm{~ns}$ & $1,02 \mathrm{~ns}$ & $0,91 \mathrm{~ns}$ & $2,00 \mathrm{~ns}$ & $0,87 \mathrm{~ns}$ & $0,97 \mathrm{~ns}$ \\
DMS (Scott-Knott 5\%) & 0,08 & 0,43 & 0,47 & 0,18 & 0,49 & 0,45 \\
CV (\%) & 3,98 & 3,90 & 6,28 & 4,26 & 2,21 & 3,18 \\
\hline
\end{tabular}

Médias seguidas de mesma letra, não diferem entre si pelo teste Scott-Knott a 5\% de probabilidade.

\section{CONCLUSÕES}

Não houve influência dos porta-enxertos sobre o comportamento ecofisiológico da cultivar Cabernet Sauvignon .

Houve tendência do porta-enxerto IAC 571-6 'Jundiaí' conferir colheita tardia à cultivar -Syrah.

Nas condições experimentais deste trabalho, a cv. Syrah, sobre os porta-enxertos 'IAC 572' e '571-6', apresentou o maior potencial para cultivo-em função do maior rendimento por planta. No entanto, a cultivar Cabernet Sauvignon apresentou a melhor relação casca/ suco, quando se considera o potencial de utilização da uva para vinificação.

\section{REFERÊNCIAS BIBLIOGRÁFICAS}

ALBERT, A. Z. Syrah/Shiraz: uma mesma uva no velho e no novo mundo. Disponível em: <http://winexperts.terra.com. br/arquivos/varietais04.html>. Acesso em: 10 mar. 2004.

ALVARENGA, A. A.; REGINA, M. de A.; FRÁGUAS, J. C.; CHALFUN, N. N. J.; SILVA, A. L. da. Influência do porta- enxerto sobre o crescimento e produção da cultivar Niágara Rosada (Vitis labrusca L. X Vitis vinífera L.) em condições de solo ácido. Ciência e Agrotecnologia, Lavras, p. 14591464, dez. 2002. Edição especial.

AMORIM, F. M. de; CAMARGO, U. A. Comportamento fenológico da cv. Shiraz no Vale do Submédio São Francisco. In: CONGRESSO BRASILEIRO DE VITICULTURA E ENOLOGIA, 10., 2003, Bento Gonçalves. Anais... Bento Gonçalves: Embrapa/CNPUV, 2003. p. 186.

BLOUIN, J.; GUIMBERTEAU, G. Maturation et maturité des raisins. Bordeaux: Féret, 2000. 151 p.

BOTTON, M.; HICKEL, E. R.; SORIA, S. J.; TEIXEIRA, I. Bioecologia e controle da ppérola-da-terra Eurhizococcus brasiliensis (Hempel, 1922) (Hemiptera: Margarodidae) na cultura da videira. Bento Gonçalves: Embrapa Uva e Vinho, 2000. 23 p. (Circular técnica, 27).

CÀSTINO, M. La qualità dell'uva. Vini d'Italia, Brescia, v. 34, n. 5, p. 23-40, 1992. 
CARBONNEAU, A. Observation sur vigne: codification des données agronomiques. Compte Rendus, Bordeaux, n. 2, p. 73-79, 1981.

CATALUÑA, E. As uvas e os vinhos. 3. ed. São Paulo: Globo, 1991. 215 p.

EMPRESA BRASILEIRA DE PESQUISA AGROPECUÁRIA. Referências bibliográficas de documentos eletrônicos. São Paulo, 2003. Disponível em: <http://www.cnpuv.embrapa.br>. Acesso em: 15 jan. 2004

FERREIRA, M. A. Influência da modificação parcial do ambiente por cobertura plástica, no microclima e em parâmetros fitotécnicos de vinhedo de 'Cabertnet Sauvignon'. 2003. 74 f. Dissertação (Mestrado em Recusos Agroambientais) - Instituto Agronômico, Campinas, 2003.

FLEET, G. H. Wine microbiology and biotechnology. Sidney: Harwood, 1992. 508 p.

FREGONI, M. Viticoltura di qualitá. Lungodige Galtorossa: Informatore Agrário, 1998. 707 p.

GALET, P. Précis d'ampélographie pratique. Montpellier: Délan, 1976. 266 p.

HIDALGO, L. Tratado de viticulture general. Madrid: Mundi-Prensa, 1993. 983 p.

JACKSON, R. S. Wine science. New York: Academic, 1999. $457 \mathrm{p}$.

LEÃO, P. C. de S.; SOARES, J. M. A viticultura do semi-árido brasileiro. Petrolina: Embrapa Semi-Árido, 2000. 368 p.

LIMA, M. A. C. de; DANTAS, B. F.; RIBEIRO, L. de S.; SILVA, A. L. da. Alterações nos teores de sólidos solúveis totais, de antocianinas e na acidez total titulável durante a maturação da uva 'Petite Syrah'. In: CONGRESSO BRASILEIRO DE VITICULTURA E ENOLOGIA, 10., 2003, Bento Gonçalves. Anais... Bento Gonçalves: Embrapa/ CNPUV, 2003. p. 196.

LOURENÇÃO, A. L.; TERRA, M. M.; PIRES, E. J. P.; POMMER, C. V.; AMBROSANO, G. M. B. Comportamento de porta-enxertos de videira em solo infestado. Revista de Agricultura, Piracicaba, v. 77, n. 1, p. 57-64, 2002.
PERNAMBUCO. Pernambuco será o segundo maior produtor de vinhos do País. Disponível em: <http:// www.pe.gov.br/jornal/jor10/np1.htm>. Acesso em: 12 mar. 2004.

POMMER, C. V. Cultivares de uva produzido ou introduzidos pelo IAC. In: SIMPÓSIO BRASILEIRO SOBRE UVAS DE MESA, 2000, Ilha Solteira. Anais... Ilha Solteira: [s.n.], 2000. p. 51-65.

RIZZON, L. A.; MIELE, A. Avaliação da cv. Cabernet Sauvignon para elaboração de vinho tinto. Ciência e Tecnologia de Alimentos, Campinas, v. 22, n. 2, p. 192-198, 2002.

RIZZON, L. A.; ZANUZ, M. C.; MIELE, A. Evolução da acidez durante a vinificação de uvas tintas de três regiões vitícolas do Rio Grande do Sul. Ciência e Tecnologia de Alimentos, Campinas, v. 18, n. 2, p. 179-183, 1998.

SANTOS, A. O.; PEDRO JUNIOR, M. J.; FERREIRA, M. A. Ecophysiology and yield performance of grape cabernet sauvignon cultivated under different exposures. Acta Scientiarum, Maringá, v. 26, n. 3, p. 263 $271,2004$.

SOUSA, J. S. I. de; MARTINS, F. P. Viticultura brasileira: principais variedades e suas caraterísticas. Piracicaba: FEALQ, 2002. 368 p. (Biblioteca de Ciências Agrárias Luiz de Queirós, 1).

TERRA, M. M.; POMMER, C. V.; PIRES, E. J. P. Yield of juice grape cultivars grafted on some IAC rootstocks. Revista Brasileira de Fruticultura, Cruz das Almas, v. 23, n. 2 p. 382-386, ago. 2001. Disponível em: <http:// www.scielo.br>. Acesso em: 20 fev. 2004.

UVIBRA. Dados estatísticos. Disponível em: <http:// www.uvibra.com.br/pdf/producao98_03.pdf >. Acesso em: 12 mar. 2004.

WINKLER, A. J.; COOK, J. A.; KLIEWER, W. M.; LIDER, L. A. General viticulture. Berkeley: University of California, 1974. 710 p.

ZOECKLEIN, B. W.; FULGENSANG, K. C.; GUMP, B. H.; NURY, F. F. Wine analysis and production. Maryland: Aspen, 1999. 818 p. 